\title{
Oesophageal acidification does not increase lower oesophageal sphincter pressure
}

\author{
J F Helm, B T Massey, C J Martin, W J Dodds, W J Hogan, R C Arndorfer
}

\begin{abstract}
We studied the effect of distal oesophageal acidification on lower oesophageal sphincter (LOS) pressure in normal human volunteers and in cats. The distal oesophagus was acidified by intraluminal injection of $0 \cdot 1 \mathrm{~N} \mathrm{HCl}(\mathrm{pH}$ 1.2). The LOS pressure was recorded by a sleeve device while pharyngeal and oesophageal pressures were monitored by nonperfused, water filled catheters. In normal human subjects, distal oesophageal acidification did not elicit a change in LOS pressure. In anaesthetised cats, injection of acid into the distal oesophagus elicited immediate LOS relaxation followed by a secondary peristaltic sequence. With propagation of the peristaltic sequence into the LOS, the LOS pressure abruptly increased $20-100 \mathrm{mmHg}$ and gradually returned to the preinjection value over 15-180 s. In the one instance in which we were able to acidify the distal oesophagus without evoking secondary peristalsis, the LOS pressure did not change. Injection of saline into the distal oesophagus evoked a response in the LOS and oesophageal body that was indistinguishable from that seen with acid. We conclude that contrary to common belief, distal oesophageal acidification itself does not affect LOS pressure in man or the cat.
\end{abstract}

Acidification of the human distal oesophagus is believed to cause a reflex increase in the lower oesophageal sphincter (LOS) pressure,' as has been reported to occur in the cat. ${ }^{2-4}$ In man, however, the effect of distal oesophageal acidification on LOS pressure has never been directly tested by instilling acid into the oesophagus. The purpose of this study was to: (i) determine the effect of acidification of the human distal oesophagus on LOS pressure, and (ii) compare the LOS response with oesophageal acidification in man with that in the cat. Unexpectedly, we found that distal oesophageal acidification does not affect LOS pressure in either human subjects or the cat.

\section{Methods}

\section{SUBJECTS}

We studied six male volunteers, aged 20-38 years. All volunteers were healthy and without a history of heartburn. The study was approved by the Human Research Review Committee of the Medical College of Wisconsin.

Volunteers were studied in the supine position after a fast of at least six hours. During each study, pressures from the oesophageal body, LOS, and stomach were recorded by a mano- metric catheter assembly (Arndorfer Medical Specialties, Greendale, Wisconsin, USA) constructed from an extruded, multilumen polyethylene tube $(4.7 \mathrm{~mm}$ od, $0.8 \mathrm{~mm}$ id). A $6 \mathrm{~cm}$ long Dent sleeve device attached to the distal end of the multilumen tube permitted continuous monitoring of the LOS pressure. ${ }^{56}$ Oesophageal body pressures were monitored by six lateral recording orifices spaced at $3 \mathrm{~cm}$ intervals along the length of the multilumen tube, beginning with an orifice just proximal to the sleeve device. An orifice at the distal end of the sleeve device allowed recording of pressure within the stomach. The sleeve device and the gastric recording orifice were each perfused with water at a rate of $0.5 \mathrm{ml} / \mathrm{min}$ by a minimally compliant pneumohydraulic capillary infusion system (Arndorfer Medical Specialties). ${ }^{7}$ The catheter lumens used to record pressures from the oesophageal body were filled, but not perfused with water. Each lumen was connected to a pressure transducer (model P23Db, Gould Statham Inc., Oxnard, California, USA), the output of which was recorded on a Beckman polygraph (Sensormedics Corp., Anaheim, California, USA). After naso-oesophageal intubation, the LOS was located by a pull through and the sleeve device was positioned so as to straddle the LOS. To monitor distal oesophageal $\mathrm{pH}$, a $\mathrm{pH}$ electrode (Model MI-506, Microelectrodes, Inc., Londonderry, New Hampshire, USA) was passed transnasally and stationed $3 \mathrm{~cm}$ proximal to the sleeve device. The polygraph event marker was used by subjects to indicate that they had swallowed spontaneously.

We first monitored the resting LOS pressure for 10 minutes in all volunteers. Then, as a control, a $5 \mathrm{ml}$ water bolus was injected into the distal oesophagus over 10-20 s through the recording orifice located $6 \mathrm{~cm}$ proximal to the sleeve device. For the next 10 minutes, water was perfused through this orifice at a rate of $1 \mathrm{ml} / \mathrm{min}$. After the control period, a $5 \mathrm{ml}$ bolus of $0.1 \mathrm{~N} \mathrm{HCl}(\mathrm{pH} 1 \cdot 2)$ was injected into the distal oesophagus over 10-20 s. Thereafter, the distal oesophagus was perfused with acid at a rate of $1 \mathrm{ml} / \mathrm{min}$ to maintain an acid $\mathrm{pH}$ for the next $10 \mathrm{~min}$.

End expiratory LOS and gastric pressures in the volunteers were measured for consecutive one minute periods by planimetry. ${ }^{8}$ The mean LOS pressure for each one minute period was referenced to the corresponding gastric pressure taken as zero. Before planimetry, physiologic variations in LOS pressure associated with oesophageal peristalsis were edited. Minute to minute differences in basal LOS pressure during the course of the study were tested for statistical significance by analysis of variance.

For comparison with the effect of distal oeso- 


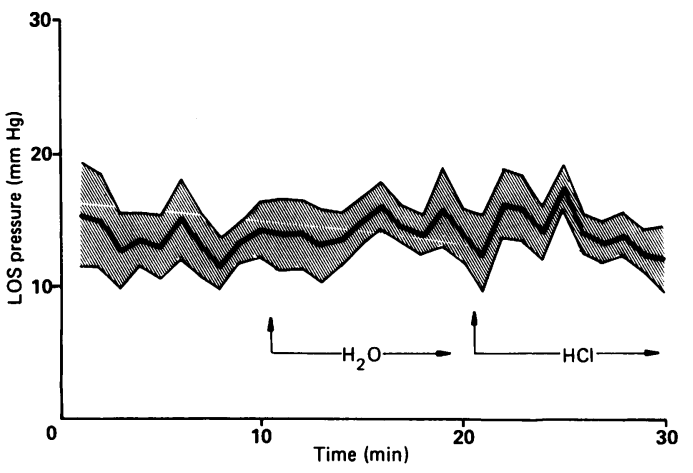

Figure 1: LOS pressure for consecutive one minute periods in six volunteers. The mean $L O S$ pressure for one minute periods is indicated by the wide line, while the shaded area represents ISE from the mean. The vertical arrows mark the injection of a $5 \mathrm{ml}$ bolus of water of $0 \cdot 1 \mathrm{~N} \mathrm{HCl}$. The horizontal arrows indicate perfusion of the oesophagus with water or $0.1 \mathrm{~N} \mathrm{HCl}$ at $1 \mathrm{ml} / \mathrm{min}$. The LOS pressure did not differ significantly from minute to minute during the study $(p>0 \cdot 25)$, irrespective of whether or not the distal oesophagus was acidified.

phageal acidification in man we studied six adult cats weighing 3-4.5 kg. Anaesthesia was induced with ketamine hydrochloride, $75 \mathrm{mg} \mathrm{im}$, and maintained with $10 \mathrm{mg}$ iv boluses as needed. Pressures were recorded from the oesophageal body, LOS, and stomach using a manometric catheter assembly similar to that used in the human studies, but of smaller dimensions. The lateral recording orifices were spaced at $2 \mathrm{~cm}$ intervals, while the sleeve device was $4 \mathrm{~cm}$ long. Pressure was also recorded from the pharynx in three animals by a non-perfused, water filled, $2 \mathrm{~mm}$ polyvinyl manometric catheter. Distal oesophageal $\mathrm{pH}$ was monitored by a $\mathrm{pH}$ electrode stationed at the proximal end of the sleeve device.

The effect of intraluminal acid on LOS pressure was tested first in three cats, using the method for oesophageal acidification described by Reynolds and colleagues. ${ }^{2-4}$ To acidify the oesophagus, a $2 \mathrm{ml}$ bolus of $0 \cdot 1 \mathrm{~N} \mathrm{HCl}$ was injected into the distal oesophagus over $10 \mathrm{~s}$ via

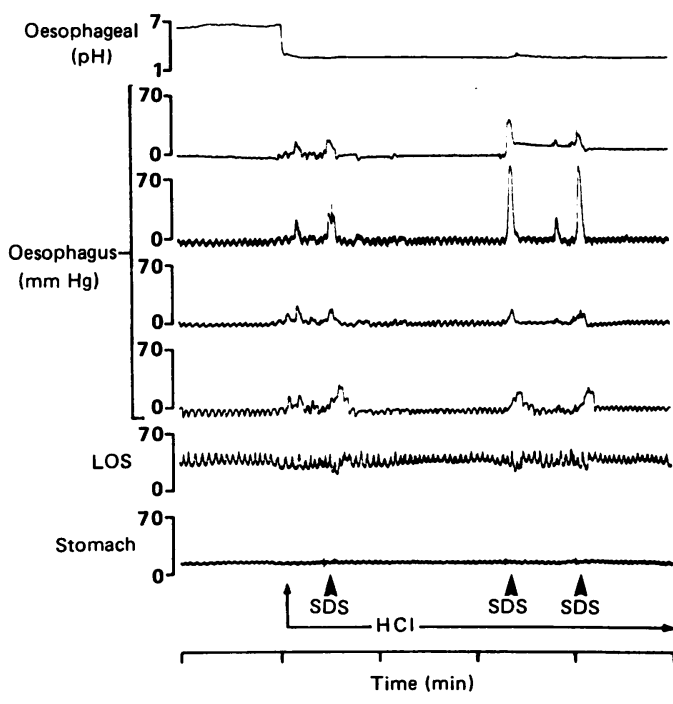

Figure 2: Effect of distal oesophageal acidification on human $L O S$ pressure. The vertical arrow marks the injection of a $5 \mathrm{ml}$ bolus of $0.1 \mathrm{~N} \mathrm{HCl}$. The horizontal arrow indicates perfusion of the oesophagus with $0 \cdot 1 \mathrm{~N} \mathrm{HCl}$ at $1 \mathrm{ml} / \mathrm{min}$. Spontaneous dry swallows are denoted by SDS. With acidification of the distal esophagus, the LOS pressure did not change other than for the physiologic variation associated with spontaneous swallows.

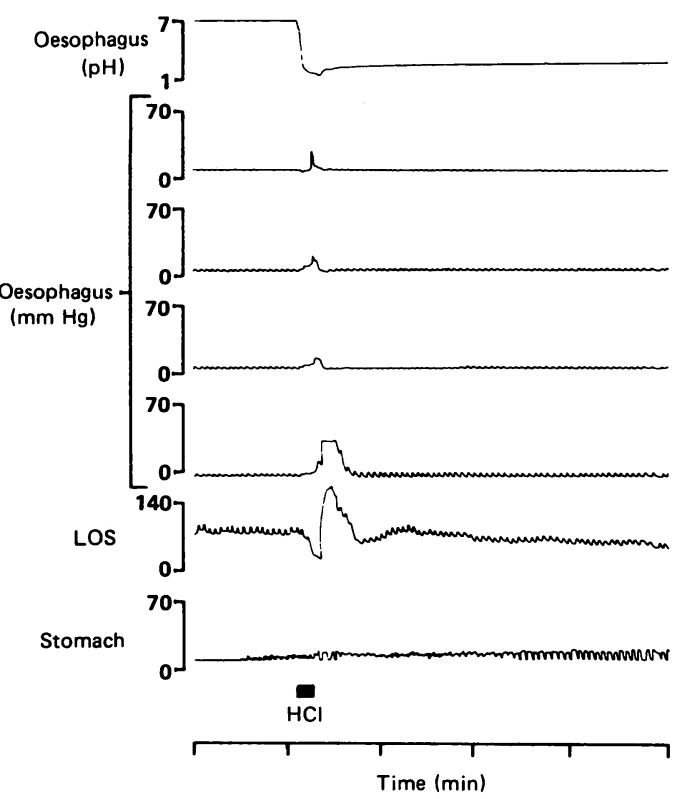

Figure 3: Effect of distal esophageal acidification on feline $L O S$ pressure. The bar indicates the 10 sinterval over which a $2 \mathrm{ml}$ bolus of $0 \cdot 1 \mathrm{~N} \mathrm{HCl}$ was injected. With distal oesophageal acidification, the only changes in LOS pressure were those associated with secondary peristalsis evoked by bolus injection.

the recording orifice $2 \mathrm{~cm}$ proximal to the sleeve device. Then, the LOS pressure was monitored for the next five minutes. As a control, a $2 \mathrm{ml}$ bolus of $0.9 \% \mathrm{NaCl}$ was substituted for the acid bolus. Injections of acid and saline were alternated until three boluses of each had been tested in each animal. After testing an acid bolus, we attempted to clear acid from the oesophagus by injecting three $2 \mathrm{ml}$ saline boluses, as Reynolds and colleagues had done..$^{2-4}$ We found, however, that saline boluses were ineffective in returning the oesophageal $\mathrm{pH}$ to normal. To clear acid from the oesophagus and restore a normal intraluminal $\mathrm{pH}$, it was necessary to inject three or four $2 \mathrm{ml}$ boluses of $22 \mathrm{mmol} \mathrm{NaHCO}_{3}$.

In an additional three cats, the volume of

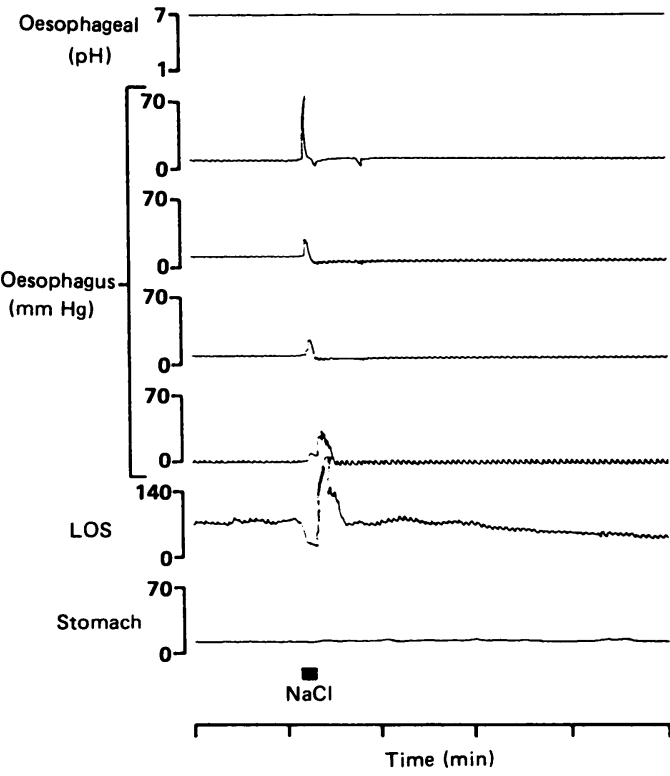

Figure 4: Effect of saline bolus injection on feline LOS

pressure. The bar indicates the 10 s interval over which a $2 \mathrm{ml}$ bolus of $0.9 \% \mathrm{NaCl}$ was injected. Injection of the saline bolus elicited only changes in LOS pressure associated with secondary peristalsis. 


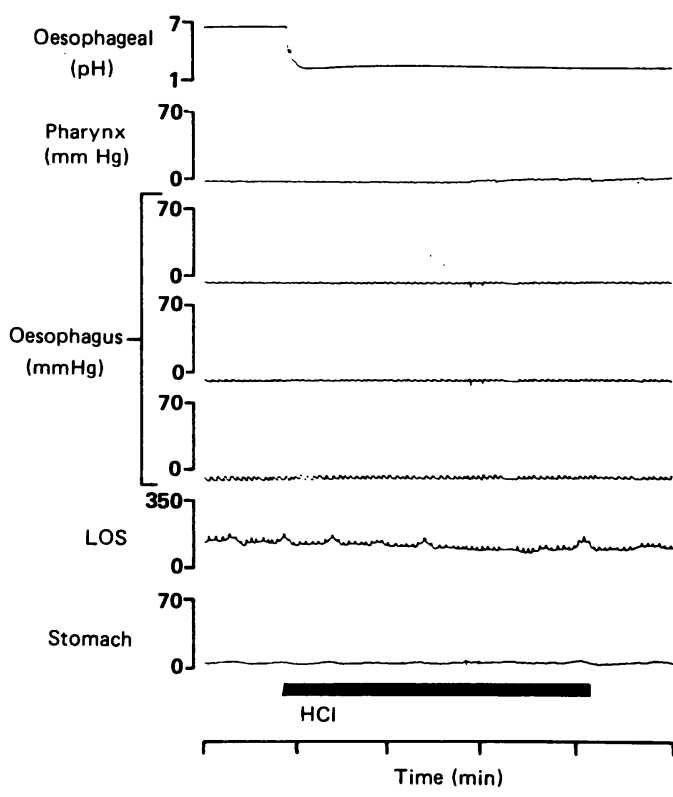

Figure 5: Effect of acidifying the feline distal oesophagus without evoking LOS relaxation and secondary peristalsis.

The bar indicates the 200 s interval over which a $2 \mathrm{ml}$ bolus of $0 \cdot 1 \mathrm{~N} \mathrm{HCl}$ was injected. With distal oesophageal

acidification, the LOS pressure did not change.

injected acid or saline was reduced to as little as $0.8 \mathrm{ml}$ and the time over which the volume was injected increased to as long as $200 \mathrm{~s}$, in an attempt to avoid eliciting a secondary peristaltic sequence upon injection of the bolus.

\section{Results}

In the six healthy volunteers, the LOS pressure did not significantly differ from minute to minute during the course of the study ( $p>0 \cdot 25$ ), irrespective of whether or not the distal oesophagus was acidified (Fig 1). Slow injection of a $5 \mathrm{ml}$ bolus of $0.1 \mathrm{~N} \mathrm{HCl}$ into the distal oesophagus did not elicit a change in LOS pressure (Fig 2). With continued acid perfusion at $1 \mathrm{ml} / \mathrm{min}$ for $10 \mathrm{~min}$, the only change in LOS pressure was the normal transient fall and post relaxation rise in pressure seen with spontaneous swallows. Acidification of the distal oesophagus for the full 10 minute perfusion was verified in each subject by $\mathrm{pH}$ electrode. None of the subjects experienced heartburn with acid perfusion.

In the first three cats tested, injection of a $2 \mathrm{ml}$ bolus of $0.1 \mathrm{~N} \mathrm{HCl}$ into the distal oesophagus over $10 \mathrm{~s}$ elicited immediate LOS relaxation followed by an oesophageal peristaltic sequence. With propagation of the peristaltic sequence into the LOS, the LOS pressure abruptly increased 20-100 $\mathrm{mmHg}$ and then gradually returned to the preinjection value over $15-180 \mathrm{~s}$ (Fig 3). Injection of a $2 \mathrm{ml}$ bolus of $0.9 \% \mathrm{NaCl}$ into the distal oesophagus over $10 \mathrm{~s}$ elicited a response in the LOS and oesophageal body that was indistinguishable from that seen with an acid bolus (Fig 4). In animals with pharyngeal catheters, it could be seen that peristaltic sequences in the oesophagus were not associated with a pharyngeal pressure wave, indicating that both acid and saline injections had evoked secondary peristalsis. The $\mathrm{pH}$ electrode verified that the distal oesophagus remained acidified for five minutes after injection of the acid bolus.
In three additional cats, we succeeded only once in our attempt to avoid eliciting secondary peristalsis by reducing the acid volume and increasing the time over which it was injected. In the one instance in which the distal oesophagus was acidified without evoking secondary peristalsis, the LOS pressure did not change (Fig 5 ). In all other test sequences, the only changes in LOS pressure that we were able to elicit by acid or saline bolus injection were those that occurred in association with secondary peristalsis, just as was seen in the first three cats tested.

\section{Discussion}

Acidification of the human distal oesophagus is believed to cause an increase in LOS pressure. The evidence cited in support of this notion comes from a study by Ahtaridis and colleagues in which acid gastro-oesophageal reflux was induced by instillation of acid into the stomach.' As an incidental finding of this earlier study, the LOS pressure was reported to rise immediately after acid gastro-oesophageal reflux and remain raised until acid was cleared from the oesophagus. This response was said to have occurred in normal volunteers, but not in patients with symptomatic gastro-oesophageal reflux disease. Evidence from this earlier study must be regarded as indirect, however, because of the means by which the distal oesophagus was acidified. Because oesophageal acidification occurred as a result of acid reflux that had been induced by gastric acid instillation, factors other than oesophageal acidification may have affected the LOS pressure. Indeed, instillation of acid just distal to the gastro-oesophageal junction has been reported to cause an increase in LOS pressure in the human ${ }^{910}$ and the dog. ${ }^{.1-13}$ In the present study, we directly determined the effect of intraluminal acid on LOS pressure by infusing a small volume of acid into the distal oesophagus. We found that acidification of the human distal oesophagus by itself does not increase LOS pressure. While we cannot explain the increase in LOS pressure after acid reflux that was reported by Ahtaridis and colleagues, our findings indicate that this increase in LOS pressure was not the result of oesophageal acidification.

Reynolds and colleagues reported that acidification of the distal feline oesophagus elicits a reflex increase in LOS pressure..$^{2-4}$ Unexpectedly, we found that distal oesophageal acidification itself did not cause the LOS pressure to increase in the cat. The only changes in LOS pressure that we were able to elicit by acid or saline bolus injection were those that occurred in association with secondary peristalsis evoked by oesophageal distension. Reynolds and colleagues noted the inconsistent presence of phasic contractions in the oesophageal body in association with oesophageal acidification. ${ }^{3}$ We do not know, however, if these contractions were peristaltic, or if the apparent LOS response to acid was instead, a response to oesophageal distension.

There is further reason to believe that the LOS response described by Reynolds and colleagues may not have been a response to oesophageal acidification itself. We found that after injecting 
acid into the oesophagus, we were unable to clear the acid by injecting a few saline boluses into the oesophagus as Reynolds and colleagues had reported..$^{2-4}$ Instead, we found it necessary to inject a bicarbonate solution into the distal oesophagus to restore the oesophageal $\mathrm{pH}$ to normal. This finding should be expected, as we previously showed that to clear acid from the oesophagus a solution must have the ability to neutralise acid, a property that saline lacks. ${ }^{1+15}$ Once acid is injected into the distal oesophagus, an acid oesophageal $\mathrm{pH}$ might persist for the remainder of the study if only saline boluses were injected into the oesophagus between test sequences. Because Reynolds and colleagues did not monitor the distal oesophageal $\mathrm{pH}$, we do not know if the oesophageal $\mathrm{pH}$ was restored to normal between test sequences, and if indeed they were testing the effects of oesophageal acidification as they believed. We cannot explain the increase in LOS pressure with oesophageal acidification that was reported by Reynolds and colleagues, however, our findings indicate that this increase in LOS pressure was not caused by oesophageal acidification itself.

Supported, in part, by grants DK39208 and DK25731 from the National Institutes of Health. A preliminary communication of this work was abstracted in Gastroenterology 1988; 95: 870, and presented at the meeting of the American Motility Society in Asilomar, California in October, 1988.
1 Ahtaridis G, Snape WJ, Cohen S. Lower esophageal sphincter pressure as an index of gastroesophageal acid reflux. Dig Dis Sci 1981; 26: 993-8.

2 Reynolds JC, Ouyang A, Cohen S. Electrically coupled intrinsic responses of feline lower esophageal sphincter. $A m$ fPhysiol 1982; 243: 415-23.

3 Reynolds JC, Ouyang A, Cohen S. A lower esophageal sphincter reflex involving substance P. Am F Physiol 1984; 246: 346-54.

4 Reynolds JC, Dukehart MR, Ouyang A. Cohen S. Interactions of bombesin and substance $P$ at the feline lower esophageal sphincter. $\mathcal{F}$ Clin Invest 1986; 77: 436-40.

5 Dent J. A new technique for continuous sphincter pressure measurement. Gastroenterology 1976; 71: 263-7.

6 Linehan JH, Dent J, Dodds WJ, Hogan WJ. Sleeve device functions as a Starling resistor to record sphincter pressure. Am F Physiol 1985; 248: 241-55.

7 Arndorfer RC, Stef JJ, Dodds WJ, Linehan JH, Hogan WJ. Improved infusion system for intraluminal manometry. Improved infusion system for

8 Dent J, Dodds WJ, Friedman RH, et al. Mechanism of gastroesophageal reflux in recumbent asymptomatic subjects. $\mathcal{F}$ Clin Invest $1980 ; 65: 256-67$.

9 Giles GR, Humphries C, Mason MC, Clark CG. Effect of pH changes on the cardiac sphincter. Gut 1969; 10: 852-6.

10 Kaye MD. On the relationship between gastric $\mathrm{pH}$ and pressure in the normal human lower oesophageal sphincter. Gut 1979; 20: 59-63.

11 Maher JW, Crandall V, Dennis MA, Woodward ER. Autonomic control of acid-stimulated lower esophageal sphincter pressure. Surg Forum 1978; 29: 430-2

12 Maher JW, Crandall V, Woodward ER. Effects of cholinergic blockade on postprandial and acid stimulated lower esophageal sphincter pressure. Am Surg 1978; 44: 758-60.

13 Sandler AD, Schlegel JF, Maher JW, Olinde AJ, McGuigan JE. Etiology of the acid-induced increase in lower esophageal sphincter pressure. Surg Forum 1987; 38: 129-31.

14 Helm JF, Dodds WJ, Hogan WJ, Soergel KH, Egide MS, Wood CM. Acid neutralizing capacity of human saliva. Gastroenterology 1982; 83: 69-74.

15 Helm JF, Dodds WJ, Riedel DR, Teeter BC, Hogan WJ, Arndorfer RC. Determinants of esophageal acid clearance in normal subjects. Gastroenterology 1983; 85: 607-12.

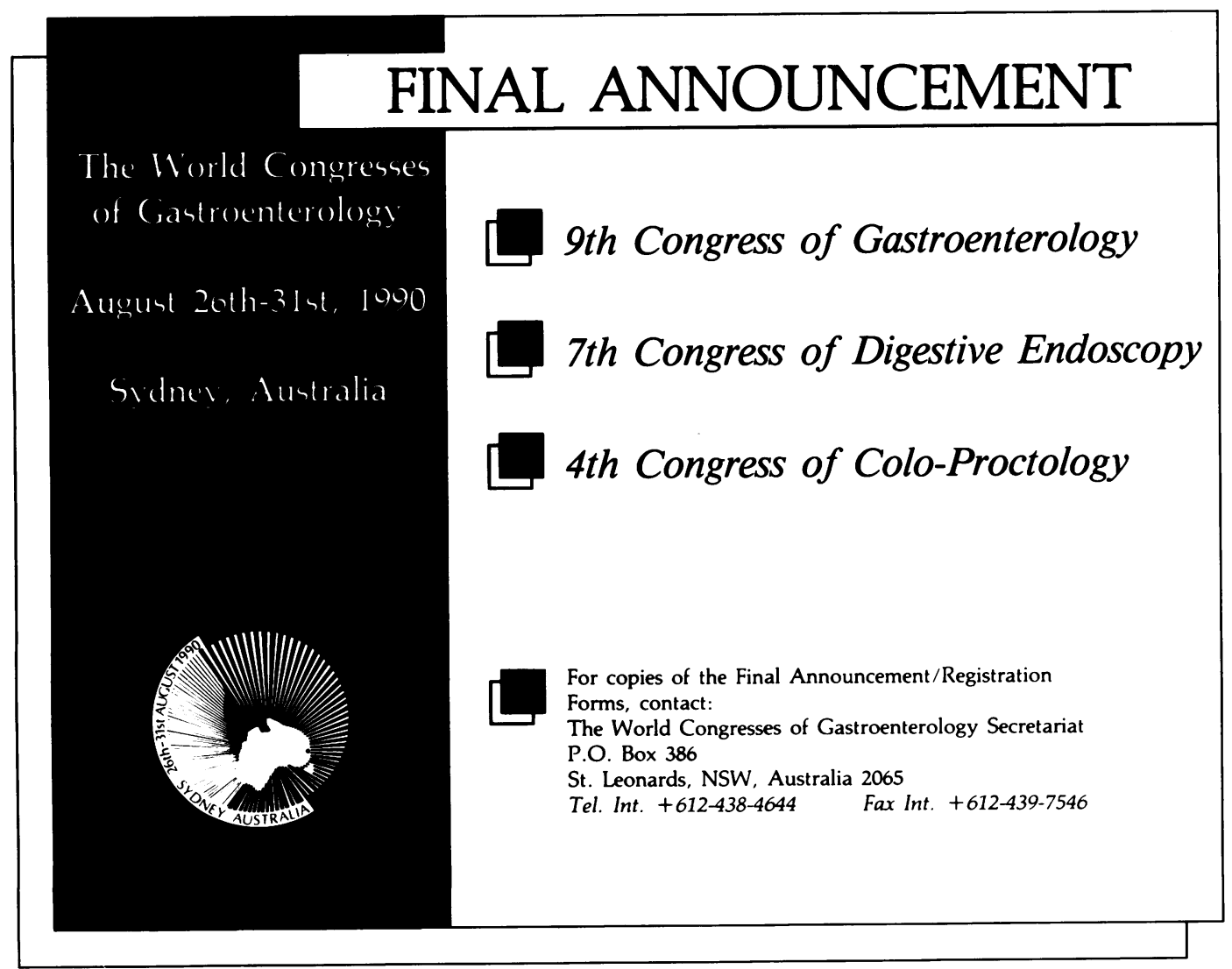

